\title{
Resveratrol and Related Compounds as Antioxidants With an Allosteric Mechanism of Action in Epigenetic Drug Targets
}

\author{
H. FARGHALI ${ }^{1}$, N. KUTINOVÁ CANOVÁ ${ }^{1}$, N. LEKIĆ ${ }^{1}$ \\ ${ }^{1}$ Institute of Pharmacology, First Faculty of Medicine, Charles University in Prague, Czech \\ Republic
}

Received July 24, 2012

Accepted October 15, 2012

On-line November 22, 2012

\begin{abstract}
Summary
The present review is intended to focus on naturally occurring cytoprotective agents such as resveratrol (trans-3,4',5trihydroxystilbene) and other related compounds, probably with similar molecular mechanisms of action and high capacity to find applications in medical fields. Several physiological aspects have been ascribed to resveratrol and similar compounds. Resveratrol, among others, has been recently described as a silent information regulator T1 (SIRT1) activator that increases AMPactivated protein kinase (AMPK) phosphorylation and reduces the oxidative damage biomarkers during aging in laboratory settings. The reports on resveratrol and other SIRT1 activators from various sources are encouraging. The pharmacological strategies for modulation of sirtuins by small molecules through allosteric mechanisms should gain a greater momentum including human research. Resveratrol and resveratrol-like molecules seem to fulfill the requirement of a new horizon in drug research since these molecules cover a growing research means as antioxidants with allosteric mechanism in epigenetic drug targets. However, one should keep in mind the challenges of extrapolation of basic research into clinical results. Overall, the issue of sirtuins in biology and disease provides an insight on therapeutic potentials of sirtuin-based therapeutics and demonstrates the high complexity of drug-targeting these modalities for human applications.
\end{abstract}

\section{Key words}

Resveratrol • SIRT1 activators • Epigenetic drug target

\section{Corresponding author}

Hassan Farghali, Institute of Pharmacology, First Faculty of Medicine, Charles University in Prague, Albertov 4, 12800 Prague 2, Czech Republic. Fax: (+420) 224968106. E-mail: hassan.farghali@lf1.cuni.cz

\section{Introduction}

Oxidative injury is well known to be associated both with the process of organism aging and with several chronic diseases that include among others, diabetes, atherosclerosis, age-related macular degeneration, cataract and Alzeheimer'disease. Moreover, oxidative stress that can be induced by toxins and environmental factors, leads to the accumulation of reactive oxygen/nitrogen species (ROS/RNS), further causing misbalance in pro-oxidant/antioxidant steady state. Protein crosslinking, lipid peroxidation, mitochondrial dysfunction and induction of cell death pathways are among the proposed mechanisms of cellular damage due to this misbalance (Jaeschke 2011, Jaeschke et al. 2012, Yeum et al. 2010). Foods, such as vegetables and fruits, rich in antioxidants are correlated with reduced risk of several chronic diseases. However, a recent meta-analysis of randomized trials, that included subjects treated with high doses of some antioxidants (e.g. beta-carotene, $\alpha$ tocopherol), demonstrated various health problems (Christen et al. 2008, Dauchet et al. 2006, Dherani et al. 2008). As expected, it is likely that physiological doses of antioxidants combination, that might be included in adequate fruit and vegetable diet, are required to establish an effective antioxidant network in vivo.

Most of the basic science literature contains 
enormous numbers of molecules that promise to ameliorate almost any disease ranging from curing cancer to slowing the aging process itself. On the other hand most of these compounds were not sufficiently evaluated in humans. The present article is not intended to overview antioxidants of various sources but rather to focus on few naturally occurring cytoprotective agents such as resveratrol and curcumin. These polyphenolic compounds found in plant have a high potential to find applications in medical fields. Resveratrol (trans-3,5,4'-trihydroxystilbene, Fig. 1) has been detected in fruits and some flowering plants, however, its major dietary sources include grapes, wine, peanuts, and peanut products.<smiles>Oc1ccc(/C=C/c2cc(O)cc(O)c2)cc1</smiles>

Resveratrol<smiles>O=c1c(O)c(-c2ccc(O)c(O)c2)oc2cc(O)cc(O)c12</smiles>

Quercetin<smiles>COc1cc(/C=C/C(=O)CC(=O)/C=C/c2ccc(O)c(OC)c2)ccc1O</smiles>

Curcumin

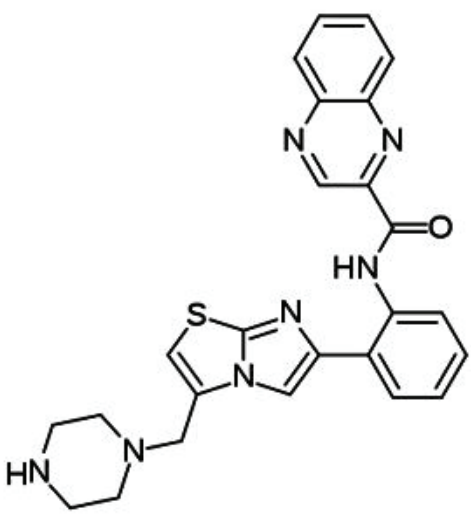

SRT1720

Fig. 1. Sirtuin activators of natural (resveratrol, curcumin and quercetin) and synthetic (SIRT1720) origin.

Curcumin (Fig. 1) belongs also to a class of natural phenols called curcuminoids that are isolated from the Indian plant Curcuma longa. This phytochemical is highly consumed worldwide as a food coloring agent, food additive and it is a main component of the popular yellow spice turmeric. For many years, this substance has been largely used as a healing agent in much of the Indian and Chinese traditional medicine. Recently, however, curcumin has attracted attention of researchers due to its speculated anti-cancerous, anti-oxidant and antiinflammatory properties (Aggarwal et al. 2007, Darvesh et al. 2012). Currently this drug is undergoing clinical trials for various cancers and neurodegenerative diseases, particularly Alzheimer's disease (Hatcher et al. 2008). Its application in the treatment of Alzheimer's diseases is based on its ability to inhibit myeloid plaque formation; as well it has been shown to improve cognitive abilities of the elderly in small scale populations ( $\mathrm{Ng}$ et al. 2006, Sikora et al. 2010).

Quercetin (Fig. 1) is another polyphenol isolated from natural sources including fruits (apples, cranberries), vegetables (onion, broccoli), tea leaves (Camellia sinensis), and grains (buckwheat). By itself, quercetin is the aglycone portion of several other flavonoid glycosides, including rutin and quercetrin, where it is bound to sugars such as rhamnose and 
rutinose. These polyphenols are also responsible for several health benefits of consuming fresh fruits and vegetables and are attractive focus of the current investigations. Several studies have shown quercetin to possess anti-inflammatory, anti-oxidant and anticancerous properties involving several different mechanisms (Chirumbolo 2010). Cardiovascular studies have demonstrated that quercetin is a potent antioxidant that prevents depletion of a potent vasodilator, nitric oxide (NO), by scavenging free $\mathrm{O}_{2}^{-}$, and thus lowering hypertension. Furthermore, in small-scale epidemiological studies done on hypertensive patients, quercetin improved blood pressure and decreased oxidized LDL concentrations (Edwards et al. 2007, Egert et al. 2009, Galleano et al. 2010). As well, a small number of studies on hepatocytes have demonstrated quercetin's antioxidant potential where it increased antioxidant capacity of the hepatocytes, decreased prooxidant and inflammatory mediators and modulated expression of several antioxidant genes (Bharrhan et al. 2012, Ghosh et al. 2011, Jo et al. 2008, Weng et al. 2011, Zhao et al. 2011). Thus, given these encouraging findings of quercetin as a potent antioxidant, it is equally important to test this substance in its potential to ameliorate other diseases.

As for the focus of this review article, resveratrol represents an example to highlight the enormous difficulties in understanding general pharmacological profiles, determining side effects, and, ultimately, establishing mechanisms of action for a natural compound that belongs to the present topic (Smoliga et al. 2012). Resveratrol has multiple biological and pharmacological properties including antioxidant and anti-inflammatory effects. These properties were observed from classical studies reporting the beneficial effects of red wine which contains resveratrol in preventing cardiovascular disease, a phenomenon known as "French Paradox". This paradox refers to the fact that, in that geographical region, they have relatively low incidence of heart disease, despite the consumption of cheese and food high in fat. Although, this beneficial effect is mainly due to alcohol, resveratrol may add additional benefit. More recently, scientists have been exploring whether resveratrol could extend lifespan as well. The intention is that resveratrol or a chemically related compound might mimic the effects of a restricted diet, which has been shown to extend the life of mice (Baur 2010). A low level of caloric intake appears to be linked with activation of the class of proteins known as sirtuins that regulate metabolism, and are activated by natural substances such as resveratrol, which is very effective, experimentally, in this respect. Recent studies in this research area gave a cautious impression in that results involving in vitro or in vivo studies often do not translate into drugs that work in humans. The experiments conducted so far have been based on a wide range of resveratrol dosage that would be impractical for human application. We have the relatively recent example of GlaxoSmithKline's concluded phase IIa study of SRT501 (a resveratrol pharmaceutical formulation in relatively high dose of resveratrol -5 grams of SRT501 in advanced multiple myeloma). It was explained by the manufacturers that SRT501 offers minimal efficacy while having a potential to indirectly exacerbate a renal complication common in the patient population with multiple myeloma. Therefore researchers are hoping to find a way to concentrate the effect into a safe dose within an effective therapeutic range (Smoliga et al. 2012).

Additionally, the protective role of resveratrol and other polyphenols against a number of hepatic injuries (e.g. cholestasis) due to oxidative damage of primary rat hepatocytes was reported by several authors including our own in vivo and in vitro results (Ara et al. 2005, Cerný et al. 2009, Cerný et al. 2011, Farghali et al. 1994a,b, Farghali et al. 2009, Hebbar et al. 2005, Lekić et al. 2011, Kutinova-Canova et al. 2012, Wu et al. 2005, Yang et al. 2005). In addition, intraperitoneal administration of resveratrol in rats with ligated bile ducts maintained antioxidant defenses and reduced liver oxidative damage and ductular proliferation. Also, other naturally occurring substances of plant origin have been claimed to possess hepatoprotective actions and these include curcumin, tetrahydrocurcumin, catechin, quercetin and beta-carotene (Auger et al. 2005, Manda and Bhatia 2003, Pari and Murugan 2004, Raza et al. 2003).

Several other physiological aspects have been ascribed to resveratrol and polyphenolic compounds. Among these effects is the ability of resveratrol to attenuate obesity-associated peripheral and central inflammation and to improve memory deficit in mice fed high-fat diet (Jeon et al. 2012). Obesity-induced diabetes was shown to be associated with chronic inflammation and is considered a risk factor for neurodegeneration. It was hypothesized that an AMP-activated protein kinase (AMPK) activator, resveratrol, which is known to exert a potent anti-inflammatory effects, would attenuate 
peripheral and central inflammation and improve memory deficit in mice fed a high-fat diet (HFD). Resveratrol treatment reduced hepatic steatosis, macrophage infiltration, and insulin resistance in HFD-fed mice. In the hippocampus of HFD-fed mice, the protein levels of pro-inflammatory tumor necrosis factor-alpha (TNF- $\alpha$ ) and ionized calcium binding adaptor molecule 1 (Iba1) expression were reduced by resveratrol treatment. Choline acetyltransferase was increased, and the phosphorylation of tau protein was decreased in the hippocampus of HFD-fed mice upon resveratrol treatment. The authors found that resveratrol significantly improved memory deficit in HFD-fed mice (Jeon et al. 2012). These findings indicate that resveratrol reverses obesity-related peripheral and central inflammation and metabolic derangements and improves memory deficit in HFD-fed diabetic mice.

Resveratrol has been found to interact with multiple molecular targets, many of them associated with inflammation and immunity, thus its potential use in therapy of immune-mediated diseases was also reported (Švajger and Jeras 2012). Indeed, it has been shown to act directly on central players of both innate and adaptive immunity, such as macrophages, lymphocytes, and dendritic cells. Generally, resveratrol has been identified as a phytoalexin, antioxidant, cyclooxygenase (COX) inhibitor, peroxisome proliferator-activated receptoralpha (PPAR- $\alpha$ ) activator, endothelial nitric oxide synthase (eNOS) inducer, silent mating type information regulation 2 homolog 1 (SIRT1) activator belonging to a superfamily known as sirtuins whose name stems after their homology to the Saccharomyces cerevisiae gene silent information regulation-2 (Sir2).

Recent reviews on resveratrol and other SIRT1 activators from various sources are encouraging (Nakata et al. 2012, Villalba et al. 2012). This is related to developing strategies to protect against diet-induced metabolic imbalance, which is necessary in order to fight against current obesity. It was suggested that the hypothalamus is a target for developing novel drugs that suppress SIRT1 degradation, as a strategy for treating metabolic syndrome. Deciphering the basic mechanism of sirtuin activators is essential to develop certain strategies to alter sirtuin activity. This is true regardless of the apparent controversy of whether in vitro activation of SIRT1 is direct or not, depending on the experimental design, and whether sirtuins may play a major role in longevity. The numerous studies on their positive effects against age-related diseases, obesity and other metabolic disorders are still valid, promising to positively influence the development of treatments to improve human health (Villalba et al. 2012).

In fact, resveratrol and similar compounds are attractive molecules that represent potential epigenetic targets in drug discovery with allosteric mechanism as will be discussed in the next sections.

\section{Resveratrol and epigenetic drug target}

Before discussing resveratrol as an epigenetic drug target, it is reasonable to shortly shed light on this topic, in so far as drug effect is concerned, in order to understand how some drugs may act. Epigenetics, at the molecular level, involves the dynamic regulation of covalent modifications to the histone proteins and DNA that influence gene expression and silencing, apoptosis, maintenance of stem cell pluripotency, X-chromosome inactivation and genomic imprinting without affecting DNA sequence (Sippl and Jung 2009). Therefore, epigenetics is considered as the conduit from genotype to phenotype. The epigenetic techniques emphasize the histone code and examine the utility of small molecule modulators of enzymes that modify histones and DNA. The dynamic remodeling of chromatin is essential to most DNA-based nuclear processes and it comes as no surprise that epigenetic changes are implicated not only in normal development but also in various diseases. The large set of structural knowledge already obtained on epigenetic targets pave the way for drug design studies to act on major biological processes such as development, aging, diseases and cancer.

Among the basic knowledge gained on catalytic domains of the main histone modifying enzymes are histone deacetylases. Histone deacetylases (HDACs) catalyze the removal of acetyl groups from epsilon-Nacetylated lysine in a nucleosomal context, ensuring the reversibility of histone acetylation. Histone deacetylation is often associated with transcriptional repression and gene silencing, since it promotes chromatin of higher order structures and the recruitment of silencers. Among this superfamily is a HDACs class III which includes $\mathrm{NAD}^{+}$-dependent deacetylases known as sirtuins (silent information regulator 2-related proteins). In the next section, we will discuss how resveratrol alters sirtuins in a specific mechanism that involves the concept of allosteric modulation. 


\section{Resveratrol as an allosteric modulator of the regulatory target SIRT1}

Allosteric modulation of a receptor or a regulatory protein results from the binding of allosteric modulators to a "regulatory site" which is different from that of the endogenous ligand (an "active site") and enhances or inhibits the effects of the endogenous ligand. Under normal circumstances, allosteric modulators act by causing a conformational change in a receptor molecule, which results in a change in the binding affinity of the endogenous ligand. In this way, an allosteric ligand modulates the receptor's activation by its primary (orthosteric) ligand, and could act like a dimmer switch in an electrical circuit, adjusting the intensity of the response. A classical example is the $\mathrm{GABA}_{\mathrm{A}}$ receptor which has two active sites, one at which the neurotransmitter gamma-aminobutyric acid (GABA) binds, as well as the benzodiazepine and general anesthetic agent regulatory binding sites. These regulatory sites can each produce positive allosteric modulation, potentiating the activity of GABA.

As a concept, allosterism was developed more than 50 years ago by Monod and coworkers to provide a framework for interpreting experimental studies on the regulation of protein function (Monod et al. 1965, Peracchi and Mozzarelli 2011). Basically, binding of a ligand at an allosteric site affects the function at a distant site exploiting protein flexibility and reshaping protein energy landscape. Both monomeric and oligomeric proteins can be allosteric. In the past decades, the behavior of allosteric systems has been analyzed in many investigations while general theoretical models and variations thereof have been steadily proposed to interpret the experimental data.

Allostery has been established as a fundamental mechanism of regulation in all organisms, governing a variety of processes that range from metabolic control to receptor function and from ligand transport to cell motility. A number of studies have shed light on how evolutionary pressures have favored and molded the development of allosteric features in specific macromolecular systems. The widespread occurrence of allostery has been recently exploited for the development and design of allosteric drugs that bind to allosteric sites leading to gain of function or loss of function. For example, small molecule activators of SIRT1 have been developed as therapeutics for the treatment of type 2 diabetes (Milne et al. 2007). Similarly to resveratrol, these compounds bind to the SIRT1 enzyme-peptide substrate complex at an allosteric site amino-terminal to the catalytic domain and increase the affinity for acetylated substrates. In the next section we will describe how resveratrol acts as an allosteric modulator of the regulatory protein SIRT1.

\section{Molecular mechanism aspects of resveratrol actions}

Several thousands of articles exist that deal with the biology and pharmacology of resveratrol, including many recent reports dealing with the molecular mechanisms of resveratrol's cytoprotection (Suchankova et al. 2009, Wong et al. 2009). The vast interest in resveratrol which inspired enormous number of studies has led to the identification of multiple molecular targets of resveratrol (Athar et al. 2009, Pervaiz and Holme 2009, Smoliga et al. 2011, Smoliga and Rundell 2011).

Several potential beneficial effects of resveratrol could be attributed to its general effects as antioxidant (Aftab et al. 2010), anti-inflammatory (Bereswill et al. 2010), alteration of drug metabolizing enzymes (Chow et al. 2010), inhibition of cyclooxygenases (Wendeburg et al. 2009), and importantly specific effects on proteins and/or signaling cascades as SIRT1 and AMPK (Fullerton et al. 2010, Xiong et al. 2011) that are summarized in an inclusive table by Smoliga et al. (2012). Hereby, we shed light on the most studied molecular mechanisms of resveratrol action, specifically with SIRT1, which controls a number of other regulatory factors associated with metabolism and inflammation as depicted in Fig. 2.

Resveratrol, as a SIRT1 activator, increased AMPK phosphorylation and reduce oxidative damage biomarkers during aging in F 2 hybrid mice (Wong et al. 2009). In addition, recent reports indicate intricate relationships between resveratrol, nuclear factors, autacoids and cytoprotection in various cells, tissues or organs. For instance in one study, resveratrol suppressed lipopolysaccharide (LPS)-induced nuclear translocation

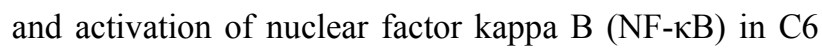
microglia demonstrating an inhibiting effect of resveratrol on pro-inflammatory responses in microglia (Kim et al. 2007). Similar finding about the protective effect of resveratrol as an inhibitor of NF- $\kappa \mathrm{B}$-mediated vascular cell adhesion molecule (VCAM-1) induction was reported (Carluccio et al. 2007). Recently, NF-кB was suggested as a target for drug therapy in liver 
diseases where resveratrol was among several agents that inhibits the aforesaid transcription factor. The fact that $\mathrm{NF}-\kappa \mathrm{B}$ has been associated with the induction of proinflammatory gene-expression makes research on agents which inhibit NF- $\mathrm{kB}$ an interesting current topic. Even other findings on experimental animals demonstrate that treatment with resveratrol can reduce structural airway remodeling changes and hyperreactivity which has important implications for the development of new therapeutic approaches to asthma (Royce et al. 2011). However, NF- $\mathrm{KB}$ has been considered as an antiinflammatory factor in certain situations and thorough understanding of the function of the diverse NF- $\kappa B$ factors is needed to examine its relation with resveratrol or similar drugs with cytoprotective effects.

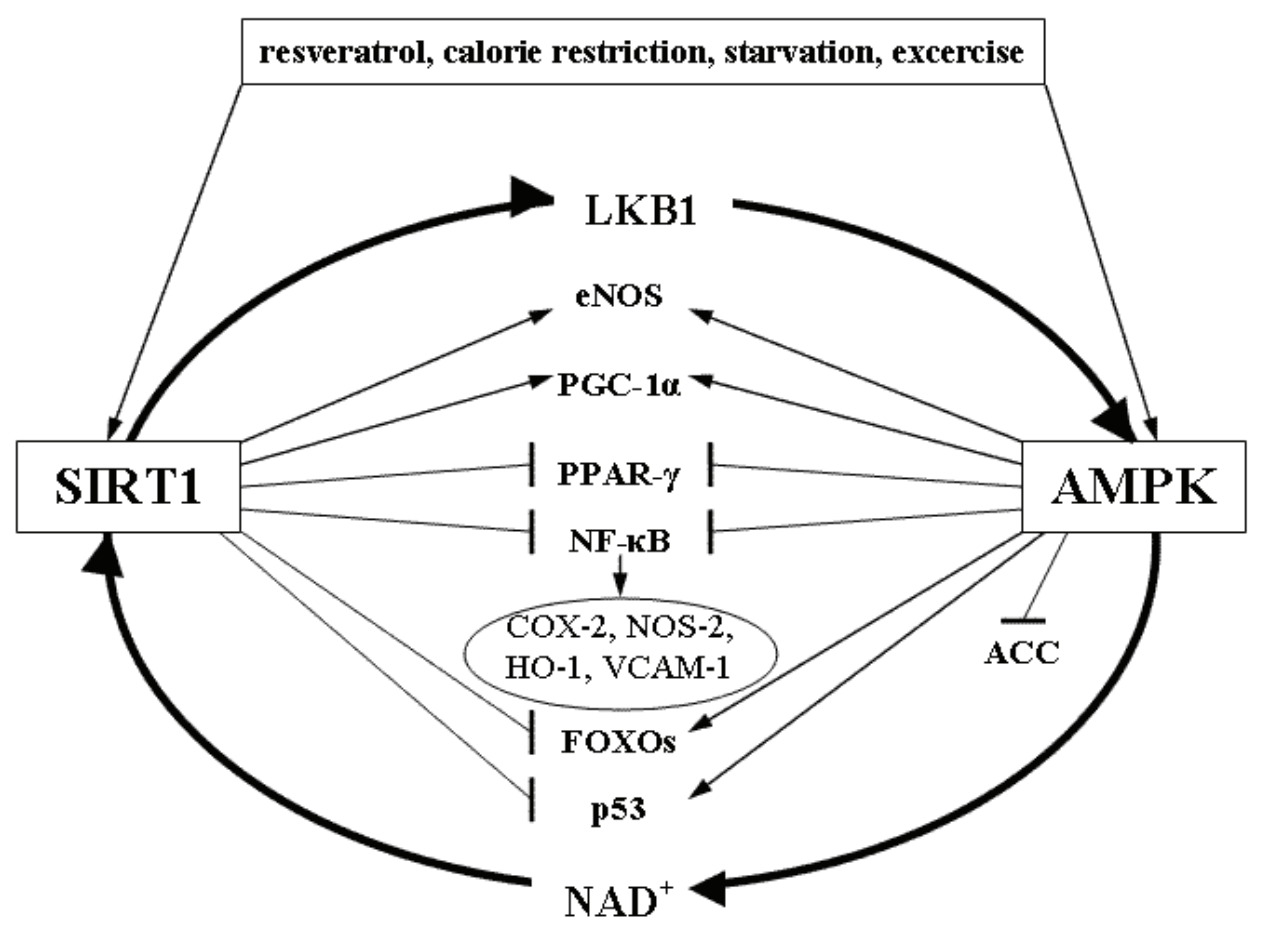

Fig. 2. Proposed molecular mechanisms by which SIRT1 and AMPK activate each other and control other regulatory factors associated with metabolism and inflammation as they are described in the text $(\rightarrow$ activation, $\perp$ inhibiton $)$. ACC, acetyl-CoA carboxylase; AMPK, AMP-activated protein kinase; eNOS (NOS-1), endothelial nitric oxide synthase; FOXOs, forkhead box-containing proteins; HO-1, inducible heme oxygenase; LKB1, liver kinase $B 1 ; N A D^{+}$, nicotinamide adenine dinucleotide; NOS-2, inducible nitric oxide synthase; PPAR- $y$, peroxisome proliferator-activated receptor- $\gamma$; PCG-1a, PPAR- $\gamma$ coactivator-1a; NF-kB, nuclear factor kappa-B; SIRT1, silent information regulator T1; VCAM-1, vascular cell adhesion molecule-1.

In our studies, we have investigated effects of resveratrol pretreatment on the enhancing action of DGalactosamine (D-GalN) on LPS-induced liver failure in rats (Farghali et al. 2009) and in immobilized perfused hepatocytes as a short term bioreactor model with a chemical prooxidant (Cerný et al. 2009, Farghali et al. 1994b). Liver function was assessed together with plasma nitrite as a measure of NO, estimation of nonenzymatic and enzymatic antioxidants was performed in plasma and liver homogenate and morphological examinations were performed using light and electron microscopy. Observations related to pharmacological increases of inducible nitric oxide synthase (NOS-2) / NO and inducible heme oxygenase (HO-1) / carbon monoxide
(CO) in fulminant hepatic failure and modulation by resveratrol were followed up by real-time reverse transcription PCR (RT-PCR) in liver tissue. In the last study we found that reduction in NO production, downregulation of NOS-2 expression, modification of oxidative stress parameters and modulation of HO-1 are among the mechanisms responsible for the cytoprotective effect of resveratrol in the LPS/D-GalN liver toxicity and tert-butylhydroperoxide-induced hepatocyte toxicity models. This led to the overall improvement in hepatotoxic markers and morphology after the hepatic insult by resveratrol pretreatment.

From these results and due to the cardinal importance of sirtuins in the mode of action of resveratrol 
through AMPK activity, the next section will focus on this intricate inter-relationship.

\section{What could be the pharmacologic benefits from SIRT1 activators?}

Sirtuins constitute a family of highly conserved nicotinamide adenine dinucleotide $\left(\mathrm{NAD}^{+}\right)$-dependent enzymes that deacetylate histones and residues of acetylated lysine. A common feature of the activity of sirtuins is their dependence on intracellular ratio of $\mathrm{NAD}^{+}$ and its reduced form NADH. Sirtuins are reported to act as sensors that detect cellular energy availability leading to metabolic benefits (Chaudhary and Pfluger 2009), as calorie restriction extends lifespan in organisms ranging from yeast to mammals (Lin et al. 2004). It is shown that the mammalian Sir2 orthologue, SIRT1 (sirtuin 1), activates a critical component of calorie restriction in mammals; that is, fat mobilization in white adipocytes (Picard et al. 2004).

Recent studies suggest a key role for the mammalian SIRT1 in adequate cellular response to metabolic stress such as nutrient deprivation or overload and that SIRT1 and its activators play role in protection from the detrimental effects of metabolic stressors (Chaudhary and Pfluger 2009, Feige et al. 2008). A key role in the regulation of adipogenesis is played by the nuclear receptor PPAR- $\gamma$ (peroxisome proliferatoractivated receptor-gamma) (Spiegelman 1998). Indeed, upon food withdrawal SIRT1 protein binds to and represses genes controlled by the fat regulator PPAR- $\gamma$, including genes mediating fat storage. SIRT1 represses PPAR- $\gamma$ by docking with its cofactors NCoR (nuclear receptor co-repressor) and SMRT (silencing mediator of retinoid and thyroid hormone receptors). Mobilization of fatty acids from white adipocytes upon fasting is compromised in SIRT1 (+/-) mice. Repression of PPAR- $\gamma$ by SIRT1 is also evident in 3T3-L1 adipocytes, where over-expression of SIRT1 attenuates adipogenesis, and RNA interference of SIRT1 enhances it. In differentiated fat cells, up-regulation of SIRT1 triggers lipolysis and loss of fat (Picard et al. 2004). As reduction in fat is sufficient to extend murine lifespan, the above-mentioned results provide a possible molecular pathway connecting calorie restriction to life extension in mammals.

In a study using liver-specific SIRT1-knockout mice, Chen et al. (2008) challenge the assumption that calorie restriction always activates SIRT1 in all tissue types by demonstrating that SIRT1 activity is reduced in the liver during calorie restriction, yet activated when mice are fed a high calorie diet. The study determines that liver-specific SIRT1-knockout mice have at least some protection, compared with wild-type mice, from accumulating fat while on a high-calorie diet. In contrast, while under calorie restriction, the liver-specific knockout mice have the same phenotype as wild-type mice. These observations suggest that hepatic SIRT1 may be inactivated during calorie restriction in normal mice and activated while on a high-calorie diet, opposite to what occurs in the muscle and the white adipose tissue that can be explained by different redox status and NAD/NADH ratio in the liver from other tissues under study conditions. It might raise the interesting possibility that SIRT1 inhibitors specifically targeted to the liver may be of benefit in treating obesity. Indeed, SIRT1 acts as cellular energy sensor that links metabolic stressors with an adequate cellular response. In the liver, SIRT1 activates PGC- $1 \alpha$ (PPAR- $\gamma$ coactivator- $1 \alpha$ ) during fasting to induce gluconeogenesis (Rodgers et al. 2005, Yang et al. 2007, Yeung et al. 2004).

Recent evidence demonstrates that there are similarities between AMPK (adenosine 5'monophosphate-activated protein kinase) and SIRT1. They have similar effects on diverse processes such as cellular fuel metabolism, inflammation, and mitochondrial function. These similarities are due to the fact that AMPK and SIRT1 have regulatory influence on each other and share many common target molecules (Ruderman et al. 2010). These findings and the concurrent demonstration by many laboratories of common activators, actions, and target molecules of SIRT1 and AMPK led to an examination of a possible linkage between SIRT1 and the primary upstream AMPK kinase, LKB1 (liver kinase B1). For example, the evidence for a SIRT1/LKB1/AMPK signaling mechanism was reported by Hou et al. (2008) who demonstrated that the ability of polyphenols (resveratrol, SI 17834) to activate AMPK in cultured HepG2 cells and mouse liver in vivo required the presence of both SIRT1 and LKB1. Likewise, in studies carried out predominantly in HepG2 cells, Suchankova et al. (2009) noted that incubation with 25 vs. $5 \mathrm{mM}$ glucose $(6 \mathrm{~h})$ or the SIRT1 inhibitor nicotinamide (10 mM, 2 h) downregulated the activity of both AMPK and SIRT1 (indicated by increased PGC- $1 \alpha$ acetylation), whereas incubation with pyruvate and the SIRT1 activator quercetin increased both of their activities. Similar effects of pyruvate and glucose on SIRT1 had been described 
previously in primary hepatocytes, suggesting that they are not unique to HepG2 cells (Rodgers et al. 2005).

Another important target for SIRT1 is NF- $\mathrm{kB}$, a regulator of many processes, including cell cycle, apoptosis, and inflammation. SIRT1 down-regulates NF$\kappa \mathrm{B}$-mediated pro-inflammatory effects by deacetylating the RelA/p65 subunit of NF- $\mathrm{kB}$ (Yang et al. 2007, Yeung et al. 2004). It is well-documented that chronic overfeeding, by increasing circulating fatty acids, might lead to inflammation, insulin resistance and injury in the liver (Mollica et al. 2011). SIRT1-overexpressing transgenic mice have decreased hepatic NF- $\mathrm{kB}$ activity, which protects from high-fat diet/lipid-induced hepatic inflammation, glucose intolerance, and nonalcoholic fatty liver disease (NAFLD) (Pfluger et al. 2008). Another study by Lee et al. (2009) finds that SIRT1-mediated attenuation of NF- $\mathrm{KB}$ signaling prevents cytokineinduced pancreatic $\beta$-cell damage.

The SIRT1 network is elegantly reviewed very recently by Kazantsev and Outeiro (2012), who discussed studies on human SIRT1, which illuminate functional relationships of gene-protein interactions, controlling major metabolic pathways and the possibility of rational design of SIRT1 effectors. Overall, the issue of "sirtuins in biology and disease" provides an insight on therapeutic potentials of sirtuin-based therapeutics and demonstrates the high complexity of drug-targeting these modalities for human applications.

\section{Do we have small molecules as sirtuin modulators?}

Milne et al. (2007) identified novel smallmolecule SIRT1 activators with 1000-fold higher pharmacologic potency compared with the structurally unrelated polyphenolic SIRT1 activator, resveratrol. Obese rodent models treated with these SIRT1 activators show improved whole-body glucose homeostasis and insulin sensitivity in liver, skeletal muscle, and adipose tissue, as well as an increased mitochondrial capacity in skeletal muscle. A very potent SIRT1 agonist, SRT1720 (Fig. 1), further increases endurance and enhances oxidative metabolism in muscle, liver, and brown adipose tissue, which might contribute to the observed protection from diet-induced obesity (Feige et al. 2008). Such increased metabolic performance might be induced by concerted deacetylation of the SIRT1 substrates PGC-1 $\alpha$, p53, FOXO-1 (forkhead box-containing protein-1) and FOX (forkhead box) proteins (a family of transcription factors that play important roles in regulating the expression of genes involved in cell growth, proliferation, differentiation, and longevity). SIRT1-mediated, indirect activation of AMPK and phosphorylation of acetyl-CoA carboxylase (ACC) might also contribute to the observed protection from NAFLD in SRT1720-treated mice fed a high-fat diet. Interesting reports on small-molecule SIRT1 activators also suggest promising new therapeutic approaches to treat metabolic diseases such as type 2 diabetes or NAFLD (Milne et al. 2007). Resveratrol, that is the most widely studied activator of SIRT1, as a small polyphenol improves insulin sensitivity and vascular function, boosts endurance, inhibits tumor formation, and ameliorates the early mortality associated with obesity in mice. Most of these effects are consistent with the modulation of SIRT1 targets, such as PGC-1 $\alpha$ and NF$\kappa \mathrm{B}$. Moreover, it also activates AMPK, inhibit cyclooxygenases, and influence a variety of other enzymes (Baur 2010). The novel activator, SRT1720, as well as various methods to manipulate $\mathrm{NAD}^{+}$ metabolism, are emerging as alternative methods to increase SIRT1 activity, and in many cases recapitulate effects of resveratrol.

The role of sirtuins in modulating redox stressor and the links between sirtuins and their oxidative/redox environment and reviewing the control mechanisms that are regulated by the activity of sirtuin deacetylase proteins was reported recently (Webster et al. 2012). It is expected that pharmacological strategies for modulation of sirtuins by small molecules through allosteric mechanisms will gain a greater momentum including human research as was suggested in earlier reports (Dai et al. 2010, Sauve 2009).

\section{Conclusion}

Although allosteric drug sites and epigenetic targets in drug discovery have been studied for several years, more studies are needed in this area. Antioxidants, which are casually used together with the synthesis of new resveratrol-like molecules, are good drug models to follow up the various molecular events responsible for potential beneficial cytoprotective effects. Indeed, resveratrol and resveratrol-like molecules seem to open new horizons in drug research since these molecules cover a growing research area on antioxidant compounds with allosteric mechanism in epigenetic drug targets. However, one should keep in mind the challenges of extrapolation of basic research into clinical results which 
is well understandable.

In fact, all data give a strong justification for further experimental and clinical studies. Moreover, in spite of the copious research articles on resveratrol, this small structure entity gives further impetus to clinical pharmaceutical chemists to do the necessary computational biological chemistry and bioinformatics to synthesize more potent molecules, which could reproduce the required pharmacological and clinical effects. We need to investigate all about effects of resveratrol and similar compounds in various models in vitro and in vivo and then reassemble the results and perform, whenever possible, human studies that are very much lacking.

\section{Conflict of Interest}

There is no conflict of interest.

\section{Acknowledgements}

This work was supported by the research project PRVOUK-P25/LF1/2.

\section{References}

AFTAB N, LIKHITWITAYAWUID K, VIEIRA A: Comparative antioxidant activities and synergism of resveratrol and oxyresveratrol. Nat Prod Res 24: 1726-1733, 2010.

AGGARWAL BB, SUNDARAM C, MALANI N, ICHIKAWA H: Curcumin: the Indian solid gold. Adv Exp Med Biol 595: 1-75, 2007.

ARA C, KIRIMLIOGLU H, KARABULUT AB, COBAN S, AY S, HARPUTLUOGLU M, KIRIMLIOGLU V, YILMAZ S: Protective effect of resveratrol against oxidative stress in cholestasis. J Surgical Res 127: 112$117,2005$.

ATHAR M, BACK JH, KOPELOVICH L, BICKERS DR, KIM AL: Multiple molecular targets of resveratrol: anticarcinogenic mechanisms. Arch Biochem Biophys 486: 95-102, 2009.

AUGER C, TEISSEDRE PL, GERAIN P, LEQUEUX N, BORNET A, SERISIER S, BESANCON P, CAPORICCIO B, CRISTOL JP, ROUANET JM: Dietary wine phenolics catechin, quercetin, and resveratrol efficiently protect hypercholesterolemic hamsters against aortic fatty streak accumulation. J Agric Food Chem 53: 2015-2021, 2005.

BAUR JA: Resveratrol, sirtuins, and the promise of a DR mimetic. Mech Ageing Dev 131: 261-269, 2010.

BERESWILL S, MUÑOZ M, FISCHER A, PLICKERT R, HAAG LM, OTTO B, KÜHL AA, LODDENKEMPER C, GÖBEL UB, HEIMESAAT MM: Anti-inflammatory effects of resveratrol, curcumin and simvastatin in acute small intestinal inflammation. PLoS One 5: e15099, 2010.

BHARRHAN S, CHOPRA K, ARORA SK, TOOR JS, RISHI P: Down-regulation of NF-kB signaling by polyphenolic compounds prevents endotoxin-induced liver injury in a rat model. Innate Immun 18: 70-79, 2012.

CARLUCCIO MA, ANCORA MA, MASSARO M, CARLUCCIO M, SCODITTI E, DISTANTE A, STORELLI C, DE CATERINA R: Homocysteine induces VCAM-1 gene expression through NF-kappaB and NAD $(\mathrm{P}) \mathrm{H}$ oxidase activation: protective role of Mediterranean diet polyphenolic antioxidants. Am J Physiol 293: H2344H2354, 2007.

CERNÝ D, KUTINOVÁ CANOVÁ N, MARTÍNEK J, HORÍNEK A, KMONÍCKOVÁ E, ZÍDEK Z, FARGHALI H: Effects of resveratrol pretreatment on tert-butylhydroperoxide induced hepatocyte toxicity in immobilized perifused hepatocytes: involvement of inducible nitric oxide synthase and hemoxygenase-1. Nitric Oxide 20: $1-8,2009$.

CERNÝ D, LEKIĆ N, VÁŇOVÁ K, MUCHOVÁ L, HOŘÍNEK A, KMONÍČKOVÁ E, ZÍDEK Z, KAMENÍKOVÁ L, FARGHALI H: Hepatoprotective effect of curcumin in lipopolysaccharide/-galactosamine model of liver injury in rats: relationship to HO-1/CO antioxidant system. Fitoterapia 82: 786-791, 2011.

CHAUDHARY N, PFLUGER PT: Metabolic benefits from Sirt1 and Sirt1 activators. Curr Opin Clin Nutr Metab Care 12: 431-437, 2009.

CHEN D, BRUNO J, EASLON E, LIN SJ, CHENG HL, ALT FW, GUARENTE L: Tissue-specific regulation of SIRT1 by calorie restriction. Genes Dev 22: 1753-1757, 2008.

CHIRUMBOLO S: The role of quercetin, flavonols and flavones in modulating inflammatory cell function. Inflamm Allergy Drug Targets 9: 263-285, 2010. 
CHOW HH, GARLAND LL, HSU CH, VINING DR, CHEW WM, MILLER JA, PERLOFF M, CROWELL JA, ALBERTS DS: Resveratrol modulates drug- and carcinogen-metabolizing enzymes in a healthy volunteer study. Cancer Prev Res (Phila) 3: 1168-1175, 2010.

CHRISTEN WG, LIU S, GLYNN RJ, GAZIANO JM, BURING JE: Dietary carotenoids, vitamins C and E, and risk of cataract in women: a prospective study. Arch Ophthalmol 126: 102-109, 2008.

DAI H, KUSTIGIAN L, CARNEY D, CASE A, CONSIDINE T, HUBBARD BP, PERNI RB, RIERA TV, SZCZEPANKIEWICZ B, VLASUK GP, STEIN RL: SIRT1 activation by small molecules: kinetic and biophysical evidence for direct interaction of enzyme and activator. J Biol Chem 285: 32695-32703, 2010.

DARVESH AS, AGGARWAL BB, BISHAYEE A: Curcumin and liver cancer: a review. Curr Pharm Biotechnol 13: 218-228, 2012.

DAUCHET L, AMOUYEL P, HERCBERG S, DALLONGEVILLE J: Fruit and vegetable consumption and risk of coronary heart disease: a meta-analysis of cohort studies. J Nutr 136: 2588-2593, 2006.

DHERANI M, MURTHY GV, GUPTA SK, YOUNG IS, MARAINI G, CAMPARINI M, PRICE GM, JOHN N, CHAKRAVARTHY U, FLETCHER AE: Blood levels of vitamin C, carotenoids and retinol are inversely associated with cataract in a North Indian population. Invest Ophthalmol Vis Sci 49: 3328-3335, 2008.

EDWARDS RL, LYON T, LITWIN SE, RABOVSKY A, SYMONS JD, JALILI T: Quercetin reduces blood pressure in hypertensive subjects. J Nutr 137: 2405-2411, 2007.

EGERT S, BOSY-WESTPHAL A, SEIBERL J, KURBITZ C, SETTLEER U, PLACHTA-DANIELZIK S, WAGNER AE, FRANK J, SCHREZENMEIR J, RIMBACH G, WOLFFRAM S, MULLER MJ: Queretin reduces systolic blood pressure and plasma oxidised low-density lipoprotein concentrations in overweight subjects with a highcardiovascular disease risk phenotype: a double blinded, placebo-controlled cross-over study. Br J Nutr 102: 1065-1074, 2009.

FARGHALI H, KAMENÍKOVÁ L, HYNIE S: The concept of application of immobilized and perfused mammalian cells (a bioreactor model) in biomedical research. Physiol Res 43: 117-120, 1994a.

FARGHALI H, KAMENÍKOVÁ L, MARTÍNEK J, LINCOVÁ D, HYNIE S: Preparation of functionally active immobilized and perfused mammalian cells: an example of the hepatocyte bioreactor. Physiol Res 43: 121-125, 1994b.

FARGHALI H, CERNÝ D, KAMENÍKOVÁ L, MARTÍNEK J, HORÍNEK A, KMONÍCKOVÁ E, ZÍDEK Z: Resveratrol attenuates lipopolysaccharide-induced hepatitis in D-Galactosamine sensitized rats: role of nitric oxide synthase 2 and heme oxygenase-1. Nitric Oxide 21: 216-225, 2009.

FEIGE JN, LAGOUGE M, CANTO C, STREHLE A, HOUTEN SM, MILNE JC, LAMBERT PD, MATAKI C, ELLIOTT PJ, AUWERX J: Specific SIRT1 activation mimics low energy levels and protects against dietinduced metabolic disorders by enhancing fat oxidation. Cell Metab 8: 347-358, 2008.

FULLERTON MD, STEINBERG GR: SIRT1 takes a backseat to AMPK in the regulation of insulin sensitivity by resveratrol. Diabetes 59: 551-553, 2010.

GALLEANO M, PECHANOVA O, FRAGA CG: Hypertension, nitric oxide, oxidants, and dietary plant polyphenols. Curr Pharm Biotechnol 11: 837-848, 2010.

GHOSH A, MANDAL AK, SARKAR S, DAS N: Hepatoprotective and neuroprotective activity of liposomal quercetin in combating chronic arsenic induced oxidative damage in liver and brain of rats. Drug Deliv 18: 451-459, 2011.

HATCHER H, PLANALP R, CHO J, TORTI FM, TORTI SV: Curcumin: from ancient medicine to current clinical trials. Cell Mol Life Sci 65: 1631-1652, 2008.

HEBBAR V, SHEN G, HU R, KIM BR, CHEN C, KORYTKO PJ, CROWELL JA, LEVINE BS, KONG AN: Toxicogenomics of resveratrol in rat liver. Life Sci 76: 2299-2314, 2005.

HOU X, XU S, MAITLAND-TOOLAN KA, SATO K, JIANG B, IDO Y, LAN F, WALSH K, WIERZBICKI M, VERBEUREN TJ, COHEN RA, ZANG M: SIRT1 regulates hepatocyte lipid metabolism through activating AMP-activated protein kinase. J Biol Chem 283: 20015-20026, 2008.

JAESCHKE H: Reactive oxygen and mechanisms of inflammatory liver injury: present concepts. J Gastroenterol Hepatol 26 (Suppl 1): 173-179, 2011. 
JAESCHKE H, MCGILL MR, RAMACHANDRAN A: Oxidant stress, mitochondria, and cell death mechanisms in drug-induced liver injury: lessons learned from acetaminophen hepatotoxicity. Drug Metab Rev 44: 88-106, 2012.

JEON BT, JEONG EA, SHIN HJ, LEE Y, LEE DH, KIM HJ, KANG SS, CHO GJ, CHOI WS, ROH GS: Resveratrol attenuates obesity-associated peripheral and central inflammation and improves memory deficit in mice fed a high-fat diet. Diabetes 61: 1444-1454, 2012.

JO HY, KIM Y, NAM SY, LEE BJ, KIM YB, YUN YW, AHN B: The inhibitory effect of quercitin gallate on iNOS expression induced by lipopolysaccharide in BALB/C mice. J Vet Sci 9: 267-272, 2008.

KAZANTSEV AG, OUTEIRO TF: Editorial on special topic: sirtuins in metabolism, aging, and disease. Front Pharmacol 3: 71, 2012.

KIM YA, KIM GY, PARK KY, CHOI YH: Resveratrol inhibits nitric oxide and prostaglandin E2 production by lipopolysaccharide-activated C6 microglia. J Med Food 10: 218-224, 2007.

KUTINOVA-CANOVA N, GAIER N, FARGHALI H: Perspectives on pharmacological and clinical benefits from SIRT1 (silent information regulator T1) activators in oxidative damage. (in Czech) Cas Lek Cesk 151: 187189, 2012.

LEE JH, SONG MY, SONG EK, KIM EK, MOON WS, HAN MK, PARK JW, KWON KB, PARK BH: Overexpression of SIRT1 protects pancreatic beta-cells against cytokine toxicity by suppressing the nuclear factor-kappaB signaling pathway. Diabetes 58: 344-351, 2009.

LEKIĆ N, CERNÝ D, HOŘÍNEK A, PROVAZNÍK Z, MARTÍNEK J, FARGHALI H: Differential oxidative stress responses to D-galactosamine-lipopolysaccharide hepatotoxicity based on real time PCR analysis of selected oxidant/antioxidant and apoptotic gene expressions in rat. Physiol Res 60:549-558, 2011.

LIN SJ, FORD E, HAIGIS M, LISZT G, GUARENTE L: Calorie restriction extends yeast life span by lowering the level of NADH. Genes Dev 18: 12-16, 2004.

MANDA K, BHATIA AL: Role of beta-carotene against acetaminophen-induced hepatotoxicity in mice. Nutr Res 23: 1097-1103, 2003.

MILNE JC, LAMBERT PD, SCHENK S, CARNEY DP, SMITH JJ, GAGNE DJ, JIN L, BOSS O, PERNI RB, VU CB, BEMIS JE, XIE R, DISCH JS, NG PY, NUNES JJ, LYNCH AV, YANG H, GALONEK H, ISRAELIAN $\mathrm{K}$, CHOY W, IFFLAND A, LAVU S, MEDVEDIK O, SINCLAIR DA, OLEFSKY JM, JIROUSEK MR, ELLIOTT PJ, WESTPHAL CH: Small molecule activators of SIRT1 as therapeutics for the treatment of type 2 diabetes. Nature 450: 712-716, 2007.

MOLLICA MP, LIONETTI L, PUTTI R, CAVALIERE G, GAITA M, BARLETTA A: From chronic overfeeding to hepatic injury: role of endoplasmic reticulum stress and inflammation. Nutr Metab Cardiovasc Dis 21: 222230, 2011.

MONOD J, WYMAN J, CHANGEUX JP: On the nature of allosteric transitions: a plausible model. J Mol Biol 12: 88$118,1965$.

NAKATA R, TAKAHASHI S, INOUE H: Recent advances in the study on resveratrol. Biol Pharm Bull 35: 273-279, 2012.

NG TP, CHIAM PC, LEE T, CHUA HC, LIM L, KUA EH: Curry consumption and cognitive function in the elderly. Am J Epidemiol 164: 898-906, 2006.

PARI L, MURUGAN P: Protective role of tetrahydrocurcumin against erythromycin estolate-induced hepatotoxicity. Pharmacol Res 49: 481-486, 2004.

PERACCHI A, MOZZARELLI A: Exploring and exploiting allostery: models, evolution, and drug targeting. Biochim Biophys Acta 1814: 922-933, 2011.

PERVAIZ S, HOLME AL: Resveratrol: its biologic targets and functional activity. Antioxid Redox Signal 11: 28512897, 2009.

PFLUGER PT, HERRANZ D, VELASCO-MIGUEL S, SERRANO M, TSCHÖP MH: Sirt1 protects against high-fat diet-induced metabolic damage. Proc Natl Acad Sci U S A 105: 9793-9798, 2008.

PICARD F, KURTEV M, CHUNG N, TOPARK-NGARM A, SENAWONG T, MACHADO DE OLIVEIRA R, LEID M, MCBURNEY MW, GUARENTE L: Sirt1 promotes fat mobilization in white adipocytes by repressing PPAR-gamma. Nature 429: 771-776, 2004. 
RAZA M, AHMAD M, GADO A, AL-SHABANAH OA: A comparison of hepatoprotective activities of aminoguanidine and $\mathrm{N}$-acetylcysteine in rat against the toxic damage induced by azathioprine. Comp Biochem Physiol C Toxicol Pharmacol 134: 451-456, 2003.

RODGERS JT, LERIN C, HAAS W, GYGI SP, SPIEGELMAN BM, PUIGSERVER P: Nutrient control of glucose homeostasis through a complex of PGC-1alpha and SIRT1. Nature 434: 113-118, 2005.

ROYCE SG, DANG W, YUAN G, TRAN J, EL OSTA A, KARAGIANNIS TC, TANG ML: Resveratrol has protective effects against airway remodeling and airway hyperreactivity in a murine model of allergic airways disease. Pathobiol Aging Age Relat Dis 1: 7134, 2011.

RUDERMAN NB, XU XJ, NELSON L, CACICEDO JM, SAHA AK, LAN F, IDO Y: AMPK and SIRT1: a longstanding partnership? Am J Physiol Endocrinol Metab 298: E751-E760, 2010.

SAUVE AA: Pharmaceutical strategies for activating sirtuins. Curr Pharm Des 15: 45-56, 2009.

SIKORA E, SCAPAGNINI G, BARBAGALLO M: Curcumin, inflammation, ageing and age-related diseases. Immun Ageing 7: 1, 2010.

SIPPL W, JUNG M (eds): Epigenetic Targets in Drug Discovery. Volume 42. Methods and Principles in Medicinal Chemistry. MANNHOLD R, KUBINYI H, FOLKERS G (eds), WILEY-VCH Verlag, Weinheim, 2009.

SMOLIGA JM, BAUR JA, HAUSENBLAS HA: Resveratrol and health-a comprehensive review of human clinical trials. Mol Nutr Food Res 55: 1129-1141, 2011.

SMOLIGA JM, RUNDELL KW: Oxidative stress: friend and foe of the elite marathoner. J Appl Physiol 110: 287 , 2011.

SMOLIGA JM, VANG O, BAUR JA: Challenges of translating basic research into therapeutics: resveratrol as an example. J Gerontol A Biol Sci Med Sci 67: 158-167, 2012.

SPIEGELMAN BM: PPAR-gamma: adipogenic regulator and thiazolidinedione receptor. Diabetes 47: 507-514, 1998.

SUCHANKOVA G, NELSON LE, GERHART-HINES Z, KELLY M, GAUTHIER MS, SAHA AK, IDO Y, PUIGSERVER P, RUDERMAN NB: Concurrent regulation of AMP-activated protein kinase and SIRT1 in mammalian cells. Biochem Biophys Res Commun 378: 836-841, 2009.

ŠVAJGER U, JERAS M: Anti-inflammatory effects of resveratrol and its potential use in therapy of immune-mediated diseases. Int Rev Immunol 31: 202-222, 2012.

VILLALBA JM, DE CABO R, ALCAIN FJ: A patent review of sirtuin activators: an update. Expert Opin Ther Pat 22: 355-367, 2012.

WEBSTER BR, LU Z, SACK MN, SCOTT I: The role of sirtuins in modulating redox stressors. Free Radic Biol Med 52: 281-290, 2012.

WENDEBURG L, DE OLIVEIRA AC, BHATIA HS, CANDELARIO-JALIL E, FIEBICH BL: Resveratrol inhibits prostaglandin formation in IL-1beta-stimulated SK-N-SH neuronal cells. J Neuroinflammation 6: $26,2009$.

WENG CJ, CHEN MJ, YEH CT, YEN GC: Hepatoprotection of quercetin against oxidative stress by induction of metallothionein expression through activating MAPK and PI3K pathways and enhancing NRF2 DNA-binding activity. N Biotechnol 28: 767-777, 2011.

WONG YT, GRUBER J, JENNER AM, NG MP, RUAN R, TAY FE: Elevation of oxidative-damage biomarkers during aging in F2 hybrid mice: protection by chronic oral intake of resveratrol. Free Radic Biol Med 46: 799$809,2009$.

WU SL, PAN CE, YU L, MENG KW: Immunosuppression by combined use of cyclosporine and resveratrol in a rat liver transplantation model. Transplant Proceed 37: 2354-2359, 2005.

XIONG S, SALAZAR G, PATRUSHEV N, ALEXANDER RW: FoxO1 mediates an auto-feedback loop regulating SIRT1 expression. J Biol Chem 286: 5289-5299, 2011.

YANG H, LEE MK, KIM YC: Protective activities of stilbene glycosides from Acer mono leaves against $\mathrm{H}_{2} \mathrm{O}_{2}$-induced oxidative damage in primary cultured rat hepatocytes. J Agric Food Chem 53: 4182-4186, 2005.

YANG SR, WRIGHT J, BAUTER M, SEWERYNIAK K, KODE A, RAHMAN I: Sirtuin regulates cigarette smokeinduced proinflammatory mediator release via RelA/p65 NF-kappaB in macrophages in vitro and in rat lungs in vivo: implications for chronic inflammation and aging. Am J Physiol 292: L567-L576, 2007. 
YEUM KJ, RUSSEL RM, ALDINI G: Biomarkers for reassemble the results and re-create the whole by human studies. In: Biomarkers for Antioxidant Defence and Oxidative Damage: Principles and Practical Applications. ALDINI G, YEUM KJ, NIKI E, RUSSEL RM (eds), Blackwell Publishing, Ames, Iowa, 2010, pp 3-19.

YEUNG F, HOBERG JE, RAMSEY CS, KELLER MD, JONES DR, FRYE RA, MAYO MW: Modulation of NFkappaB-dependent transcription and cell survival by the SIRT1 deacetylase. EMBO J 23: 2369-2380, 2004.

ZHAO L, WU J, YANG J, WEI J, GAO W, GUO C: Dietary quercetin supplementation increases serum antioxidant capacity and alters hepatic gene expression profile in rats. Exp Biol Med 236: 701-706, 2011. 